University of Nebraska - Lincoln

DigitalCommons@University of Nebraska - Lincoln

USDA Wildlife Services - Staff Publications

U.S. Department of Agriculture: Animal and

Plant Health Inspection Service

2022

\title{
Foot Injuries in Michigan, USA, Gray Wolves (Canis lupus), \\ 1992-2014
}

Daniel J. O'Brien

Dean E. Beyer Jr.

Erin Largent

Julie R. Melotti

Caitlin N. Ott-Conn

See next page for additional authors

Follow this and additional works at: https://digitalcommons.unl.edu/icwdm_usdanwrc

Part of the Natural Resources and Conservation Commons, Natural Resources Management and Policy Commons, Other Environmental Sciences Commons, Other Veterinary Medicine Commons, Population Biology Commons, Terrestrial and Aquatic Ecology Commons, Veterinary Infectious Diseases Commons, Veterinary Microbiology and Immunobiology Commons, Veterinary Preventive Medicine, Epidemiology, and Public Health Commons, and the Zoology Commons

This Article is brought to you for free and open access by the U.S. Department of Agriculture: Animal and Plant Health Inspection Service at DigitalCommons@University of Nebraska - Lincoln. It has been accepted for inclusion in USDA Wildlife Services - Staff Publications by an authorized administrator of DigitalCommons@University of Nebraska - Lincoln. 


\section{Authors}

Daniel J. O'Brien, Dean E. Beyer Jr., Erin Largent, Julie R. Melotti, Caitlin N. Ott-Conn, Donald H. Lonsway, Thomas M. Cooley, Robert Atkinson, Michelle Clayson, and Kelly A. Straka 


\title{
FOOT INJURIES IN MICHIGAN, USA, GRAY WOLVES (CANIS LUPUS), 1992-2014
}

\author{
Daniel J. O'Brien, ${ }^{1,4,6}$ Dean E. Beyer, Jr., ${ }^{2,4}$ Erin Largent, ${ }^{2}$ Julie R. Melotti, ${ }^{1}$ Caitlin N. Ott-Conn, ${ }^{1}$ \\ Donald H. Lonsway, ${ }^{3,4}$ Thomas M. Cooley, ${ }^{1}$ Robert Atkinson, ${ }^{2}$ Michelle Clayson, ${ }^{1}$ and Kelly A. \\ Straka $^{1,5}$ \\ ${ }^{1}$ Wildlife Disease Laboratory, Michigan Department of Natural Resources, 4125 Beaumont Road, Lansing, Michigan \\ 48910-8106, USA \\ ${ }^{2}$ Wildlife Division, Michigan Department of Natural Resources, 1990 US-41 S, Marquette, Michigan 49855, USA \\ ${ }^{3}$ Wildlife Services, Animal and Plant Health Inspection Service, US Department of Agriculture, 13025 Lake Road, \\ Ironwood, Michigan 49938-8106, USA \\ ${ }^{4}$ Retired \\ ${ }^{5}$ Current address: Wildlife Section, Minnesota Department of Natural Resources, 500 Lafayette Road, St. Paul, Minnesota \\ 55155-4020, USA \\ ${ }^{6}$ Corresponding author (email: obriend1 @ msu.edu)
}

ABSTRACT: The range of gray wolves (Canis lupus) in the contiguous US is expanding. Research and monitoring to support population recovery and management often involves capture via foothold traps. A population-level epidemiologic assessment of the effect of trap injuries on wolf survival remains needed to inform management. We describe the baseline rate, type, and severity of foot injuries of wolves born 1992-2013 in Michigan's Upper Peninsula, evaluate the reliability of field-scoring trap-related injuries, and the effect of injuries on wolf survival. We assessed foot injuries by physical and radiographic exam at postmortem and/or time of capture for 351 wolves using the International Organization for Standardization 10990-5 standard and the effects of injuries, sex, age, previous capture and body condition on survival using proportional hazards regression. We used ordinal regression to evaluate epidemiologic associations between sex, age, previous capture, body condition, cause of death and injury severity. Most wolves (53\%) experienced no physically or radiographically discernable foot injuries over their lifetimes. Among those wolves that did experience injuries, 33\% scored as mild. Foot injuries had little epidemiologically discernable effect on survival rates. Wolves with higher foot trauma scores did experience an increased risk of dying, but the magnitude of the increase was modest. Most limb injuries occurred below the carpus or tarsus, and scoring upper-limb injuries added little predictive information to population-level epidemiologic measures of survival and injury severity. There was little association between injury severity and cause of death. Based on necropsy exams, previous trap injuries likely contributed to death in only four wolves (1.1\%). Our results suggest that injuries resulting from foothold traps are unlikely to be a limiting factor in recovery and ongoing survival of the Michigan gray wolf population.

Key words: Canis lupus, foot injuries, foothold traps, gray wolf, Michigan, survival analysis.

\section{INTRODUCTION}

As of 2019, gray wolves (Canis lupus) occupy three regions in the contiguous US and are expanding into new regions via dispersal (USFWS 2019). Research and monitoring to support the recovery and management of wolves in these areas often involves wolf capture to attach telemetry collars. Biologists commonly use foothold traps for capturing wolves during these studies (e.g., Mech 1974; Kuehn et al. 1986).

Foothold traps can injure wolves, and several studies have investigated the rate and severity of injuries among different types of traps (Van Ballenberghe 1984; Kuehn et al. 1986; Frame and Meier 2007; Gese et al. 2019). A large and systematic effort to develop trapping best management practices has developed and applied pass-fail thresholds to different models of foothold traps for a number of furbearers, including wolves (White et al. 2021). All of these studies have evaluated traps designed specifically for the capture of wolves and have assessed injuries in known-trapped animals. However, eight states in which wolf populations are established allow the trapping of other furbearers, such as coyotes (Canis latrans) and bobcats (Lynx rufus), and inci- 
dental capture of wolves occurs. Typically, coyote trappers do not use models of traps designed for wolves. As a result, some wolves escape, and some of these probably experience foot injuries.

Like any injury, foot injuries can affect survival. In Michigan, O'Neil et al. (2017) reported slightly greater mortality risk for telemetered wolves incidentally caught by coyote trappers compared with those captured only by agency trappers. However, an assessment of a broader population including wolves that coyote or bobcat trappers released untreated, as well as wolves that escaped, would be valuable to inform wolf recovery and management.

Quantitative epidemiologic studies of traprelated foot injuries in large populations of wolves where the species is now recovered and established, injuries that could affect the legal status and ongoing management of the species by state natural resource agencies, are currently lacking. Here we describe the baseline rate, type, and severity of foot injuries of wolves in Michigan's Upper Peninsula, based on laboratory assessment. In addition, we evaluate the reliability of assessing trap-related injuries in the field, and the effect of foot injuries on wolf survival.

\section{MATERIALS AND METHODS}

The Michigan wolf population under the management of the Michigan Department of Natural Resources (MDNR) can be subdivided into three groups for the purposes of this study: 1) wolves captured by MDNR staff for research and population monitoring; 2) wolves accidently (incidentally) caught by licensed trappers in traps intended to catch coyotes and bobcats; and 3) wolves not known to have been caught in traps during their lifetimes.

\section{Wolf capture and processing}

Wolves were captured as part of the MDNR's wolf research program, or incidentally by licensed coyote (and occasionally bobcat) trappers.

Research-caught wolves: Research capture efforts, which were cooperative between the MDNR and US Department of Agriculture's Animal and Plant Health Inspection ServiceWildlife Services (WS), were part of an ongoing program to assess abundance and survival rates (Beyer et al. 2009; MDNR 2015). Staff of MDNR and the Wildlife Services (hereafter, research trappers) captured wolves using foot-hold traps during the spring and summer, 1997-2013. Research trapping occurs after the threat of frost has subsided and ends before 8 July, when hunting-dog field-training season opens, following methods similar to Mech (1974) and Kuehn et al. (1986). These dates help minimize the possibility that trapped animals could become hypothermic when caught overnight, and the possibility of incidentally trapping bear-hunting hounds during their typical training period. Modified Minnesota Brand 750 foot-hold traps (Minnesota Trapline Products, Inc., Pennock, Minnesota, USA) were set along roads and trails used as travel corridors to target specific packs, based on previous radiotelemetry data and winter track surveys. The stock version (before modifications to minimize injuries) of the Minnesota Brand 750 trap met best management practices standards (White et al. 2021). All traps used for research trapping were modified by rounding and smoothing all edges of the trap jaws and setting tabs to eliminate sharp edges that might cause lacerations, and an in-line shock spring was added to the trap chain to cushion lunges made by the wolf after capture. Research trappers checked traps each morning and rechecked them in the afternoon if ambient temperatures were high $(\geq 29 \mathrm{C})$ and cover for shade was limited. Research trappers placed warning signs at all road entrances to trapping areas, notifying domestic dog owners using the roads or trails that traps were present.

After capture, wolves were chemically immobilized via intramuscular injection of ketamine hydrochloride $(0.11 \mathrm{mg} / \mathrm{kg})$ and xylazine hydrochloride (2 mg/kg; Kreeger and Arnemo 2018). Research trappers determined the sex and weight and fitted captured wolves with very high frequency (VHF) or GPS collars (VHF-Telonics, Inc., Mesa, Arizona, USA; GPS-Televilt/TVP Positioning, AB, Lindesburg, Sweden; Potvin et al. 2005; Beyer et al. 2009; Vucetich et al. 2012) and monitored and recorded body temperature, pulse, and respiration as well as body condition, along with any evidence of old injuries. Beginning in 2003, research trappers also recorded which foot was captured in the trap and assessed and scored the extent of injuries related to the foothold trap using Annex C of the ISO 10990-5 standard (ISO 1999), a repeatable system for scoring injuries associated with capture by foothold traps, as detailed soon.

Incidentally caught wolves: Coyote trapping season in Michigan is open to licensed trappers from 15 October through 1 March. Coyote trappers are not required to check traps daily; 
regulations required licensed coyote trappers to check traps every $72 \mathrm{~h}$ from 2002-05 and every 48 $\mathrm{h}$ from 2005-13. Coyote trappers use a variety of different trap models; trap modification to minimize injuries varies. Coyote trappers rarely use the Minnesota Brand 750 trap used by research trappers targeting wolves. Coyote trappers occasionally catch wolves accidentally in coyote sets and routinely call MDNR staff to help release these animals. If the incidentally captured wolf is in an area where a telemetered animal would be useful to monitor pack movements, MDNR staff members immobilize the wolf and fit it with a collar, as detailed earlier. Beginning in 2003, MDNR staff also recorded the trapped foot and scored injuries related to the foot-hold trap according to the ISO standard. The MDNR staff did not systematically record the size, model, and modifications to the coyote traps. It is unknown, but likely, that some coyote trappers released incidentally caught wolves without contacting MDNR for assistance. Because no agency staff would have been present in those cases, the methods used by the coyote trappers were unknown to MDNR staff, as were any foot injuries incurred by those wolves.

Using fixed-wing aircraft, MDNR staff relocated all radiocollared wolves and determined their vital status at intervals of 1-14 d throughout each year. When staff detected a collar transmitting a mortality signal, the wolf carcass was located as soon as possible, typically within $2 \mathrm{~d}$. Staff conducted a cursory field examination to determine the preliminary cause of death; we later updated that diagnosis after necropsy at the MDNR Wildlife Disease Laboratory (WDL).

\section{Necropsy specimens}

All wolves found dead by MDNR field staff or the public and reported to MDNR, or seized from suspects by MDNR Conservation Officers as part of poaching investigations, are routinely transported to the WDL for necropsy. Because of the status of wolves as federally endangered, this protocol has been adhered to rigorously since wolf recovery began in Michigan in the late 1980s. A single pathologist (T.M.C.) and senior technician (J.R.M.) performed all necropsies during the period covered in this study. At the end of their examinations, all the legs of each wolf were severed at the radial-carpal and tibial-tarsal joints, the distal portions (hereafter referred to collectively as feet) were bagged, identified by the WDL necropsy accession number, and frozen until detailed examination.

Ages to year were determined for each wolf by examination of cementum annuli (Matson 1981). For animals younger than $1 \mathrm{yr}$, and to provide additional precision to facilitate survival analysis, all wolves were assigned a universal birthdate of 1 April (Baker 1983) and assigned $0.08 \mathrm{yr}$ of age for each month they had accumulated by the date their carcass was collected. We then added those partial year ages to their cementum age.

\section{Foot examination and postmortem injury scoring}

All wolves were scored by the same observer (D.J.O.), who was blinded to their history and physical and necropsy findings. After thawing, each set of feet was examined grossly, palpated for evidence of injuries, and any abnormalities were noted. Plain radiographs were taken of each set, one in the dorsopalmar/dorsiplantar view and the other in the lateral view. Radiographs were examined on a lightbox for evidence of injuries and abnormalities.

The presence and severity of injuries was scored using Annex C of the ISO 10990-5 standard (ISO 1999). The standard was last reviewed and confirmed in 2017. It provides two metrics for assessing trauma: a continuous scale (hereafter, trauma score) based on assignment of points for each pathologic observation noted, which are then summed; and an ordinal scale (hereafter, trauma class) in which particular lesions are categorized as mild, moderate, moderately severe, or severe. Where more than one lesion is noted on a particular animal, a standardized summary trauma class is given for the combined observations of lesions. For example, a wolf for which one lesion was considered moderate trauma and two lesions were considered mild trauma would be assigned a summary trauma class of moderately severe. Anatomic nomenclature follows that of Sisson (1975).

Data were compiled in Microsoft Access (Microsoft Corporation, Redmond, Washington, USA) for each wolf, including sex, age, whether they were known to have been captured previously, accumulated days at risk (calculated as birthdate to date of carcass collection), postmortem trauma score, and postmortem trauma class. For the subset of wolves that had been captured previously, the trauma score and trauma class recorded at the time of live capture were also recorded.

After all foot injuries were scored, the necropsy records of all wolves in the study were examined by the same observer who scored the feet (D.J.O.), for evidence of limb injuries above the carpus/tarsus and to extract body condition (scored as poor, fair, good, and very good) and the cause of death, as determined by the attending pathologist (T.M.C.). Upper-limb injuries were scored using the ISO 10990-5 standard as described earlier. 


\section{Statistical analysis}

We generated summary statistics in SAS software (version 9.4, SAS Institute, Cary, North Carolina, USA) and assessed significant differences in proportions using a two-tailed Fisher's exact test. Differences in injury scores among researchcaptured wolves and those incidentally trapped by coyote trappers were compared with wolves with no previous capture history via the Kruskal-Wallis test in R software (version 3.5.1; R Core Team 2018; R Foundation for Statistical Computing, Vienna, Austria). Where MDNR-handled wolves of either category were scored for injuries at the time of capture, those scores were compared with scores given postmortem, via a Spearman rank correlation.

We assessed the effects of foot injuries (as measured by postmortem trauma scores), sex, age, previous capture, and body condition on wolf survival using Cox proportional hazards regression, implemented using the PHREG procedure in SAS software. We used ordinal regression modeling employing cumulative logits in SAS Proc Logistic to evaluate the association of sex, age, body condition, and cause of death with the severity of foot injuries (as measured by trauma class; Stokes et al. 1995). All analyses were repeated with trauma metrics for injuries above the carpus/tarsus incorporated into the wolf's overall injury metrics, and the results were compared. We subjected sets of candidate regression models to information-theoretic model selection (Burnham and Anderson 2010). In all cases in which hypothesis testing was conducted, we considered significance attained at $P \leq 0.05$.

\section{RESULTS}

\section{Descriptive epidemiology}

The analysis included 351 wolves; 157 (45\%) were female. The mean age at necropsy was $3.3 \mathrm{yr}$ (range, 0.3-12.4 yr), encompassing wolves born 1992-2013. The population accumulated 422,998 wolf-days of follow-up time over the course of the study, with a mean of $1,205 \mathrm{~d}$ ( $\mathrm{SD}=801.8$; range, 57-4,559 d). Most wolves (185, 53\%) experienced no physically or radiographically discernable foot injuries over the course of their lifetimes. Of the 166 that experienced injuries, 54 (33\%) were mild injuries (Table 1). Injuries observed across all 351 wolves and their frequencies of occurrence are depicted in Table 2.

Across the 166 injured wolves, 216 palpable or visible (grossly or radiographically) foot
TABLE 1. Trauma scores of foot injuries among 351 Michigan, USA, gray wolves (Canis lupus) examined postmortem 2001-15. The presence and severity of foot traumas were scored using Annex C of the International Organization for Standardization (ISO)'s 10990-5 standard (ISO 1999), which provides a repeatable system for scoring injuries associated with capture by foot-hold traps. Scores based on lesion type, anatomic site, and severity are summed to produce a trauma score (continuous variable) for each wolf examined. The trauma severity categories associated with each lesion are also combined into a summary trauma class (ordinal variable) for each wolf using specific standard rules (e.g., a wolf with five mild traumas is assigned a summary trauma class of "moderately severe"). ${ }^{\mathrm{a}}$

\begin{tabular}{lrrrrc}
\hline \multicolumn{1}{c}{ Trauma } & $\begin{array}{c}\text { No. } \\
\text { wolves }\end{array}$ & Median & Mean & SD & Range \\
\hline None & 185 & NA & NA & NA & NA \\
Mild & 54 & 5 & 7.2 & 4.4 & $2-20$ \\
Moderate & 18 & 30 & 28.4 & 6.7 & $10-40$ \\
$\begin{array}{l}\text { Moderately } \\
\quad \text { severe }\end{array}$ & 44 & 50 & 61.2 & 16.7 & $35-105$ \\
$\quad$\begin{tabular}{l} 
Severe \\
\hline
\end{tabular} & 50 & 114 & 177.0 & 165.1 & $60-910$ \\
\hline
\end{tabular}

${ }^{a} \mathrm{NA}=$ not applicable.

lesions were found; 121 (73\%) of the wolves had injuries on only one foot, 36 wolves (22\%) on two feet, seven wolves $(4 \%)$ on three feet, and two wolves $(1 \%)$ on all four feet. We found that 71 wolves (43\%) had injuries on the right fore foot, $60(36 \%)$ on the left fore, $46(28 \%)$ on the right hind, and $39(23 \%)$ on the left hind. The metacarpus had the highest frequency of lesions, followed by the proximal phalanx, middle phalanx, metatarsus, and distal phalanx (Table 3). Lesions involving the tarsus (four wolves, 2\%) and carpus (one wolf, $0.6 \%$ ) were comparatively rare. Radiographically visible metal densities consistent with firearms ammunition were noted infrequently as incidental findings (11 wolves, $7 \%$ ), and rarely, associated with bony lesions (two wolves, $1 \%$ ).

Of the 351 wolves, $75(21 \%)$ had been trapped by MDNR staff for research; another 32 (9\%) had been caught incidentally by coyote trappers. The remaining wolves had no known history of having been trapped. Stratifying by those categories, $64 \%$ of wolves trapped for research, $69 \%$ of incidental 
TABLE 2. Frequency of palpable or visible (grossly or radiographically) lesions among 166 Michigan, USA, gray wolves (Canis lupus) with foot injuries from a population of 351 wolves examined postmortem 2001-15. The presence and severity of foot injuries were scored using Annex C of the International Organization for Standardization (ISO)'s 10990-5 standard (ISO 1999), which provides a repeatable system for scoring injuries associated with capture by foot-hold traps. Scores based on lesion type, anatomic site, and severity are summed to produce a trauma score for each wolf examined. The trauma severity categories associated with each lesion are also combined into a summary trauma class for each wolf using specific standard rules (e.g., a wolf with five mild traumas is assigned a summary trauma class of "moderately severe").

\begin{tabular}{|c|c|c|c|c|}
\hline Injury & $n^{\mathrm{a}}$ & $\%_{\text {inj }}^{b}$ & $\%_{\text {all }}^{c}$ & Trauma class \\
\hline Simple fracture & 52 & 31 & 15 & Moderately severe \\
\hline Minor cutaneous laceration $<2 \mathrm{~cm}$ & 31 & 19 & 8.8 & Mild \\
\hline Claw loss & 29 & 17 & 8.3 & Mild \\
\hline Major periosteal abrasion ${ }^{\mathrm{d}}$ & 28 & 17 & 8.0 & Moderate \\
\hline Major cutaneous laceration, except on foot pads & 20 & 12 & 5.7 & Mild \\
\hline Joint luxation & 16 & 9.6 & 4.6 & Moderate \\
\hline Compound or comminuted fracture & 12 & 7.2 & 3.4 & Severe \\
\hline Edematous swelling or hemorrhage & 12 & 7.2 & 3.4 & Mild \\
\hline Amputation of two digits & 10 & 6.0 & 2.8 & Moderately severe \\
\hline Amputation of three or more digits & 8 & 4.8 & 2.3 & Severe \\
\hline Amputation of one digit & 7 & 4.2 & 2.0 & Moderate \\
\hline Minor periosteal abrasion & 7 & 4.2 & 2.0 & Mild \\
\hline Minor subcutaneous soft tissue maceration or erosion (contusion) & 6 & 3.6 & 1.7 & Mild \\
\hline Any amputation above the digits & 5 & 3.0 & 1.4 & Severe \\
\hline Major laceration on footpads & 4 & 2.4 & 1.1 & Moderate \\
\hline Major subcutaneous soft tissue maceration or erosion & 3 & 1.8 & 0.9 & Moderate \\
\hline Severance of minor tendon or ligament & 2 & 1.2 & 0.6 & Moderate \\
\hline Compression fracture & 1 & 0.6 & 0.3 & Moderately severe \\
\hline Severe joint hemorrhage & 1 & 0.6 & 0.3 & Moderate \\
\hline
\end{tabular}

a Number of wolves showing condition.

${ }^{\mathrm{b}}$ Percentage of all injured wolves with this particular injury.

c Percentage of all wolves in the study with this particular injury.

${ }^{\mathrm{d}}$ Includes osteoarthritis unassociated with a visible fracture site.

TABLE 3. Frequency and anatomical location of palpable or visible (grossly or radiographically) lesions among 166 Michigan, USA, gray wolves (Canis lupus) with foot injuries, from a population of 351 wolves examined postmortem 2001-15.

\begin{tabular}{lcccccr}
\hline & \multicolumn{5}{c}{ Digit } \\
\cline { 2 - 6 } \multicolumn{1}{c}{$\begin{array}{c}\text { Anatomic } \\
\text { location }\end{array}$} & I $^{\text {a }}$ & II & III & IV & V & Total \\
\hline Metacarpus & 4 & 44 & 43 & 38 & 41 & 170 \\
Metatarsus & NA & 27 & 16 & 17 & 21 & 81 \\
Proximal phalanx & 3 & 33 & 25 & 24 & 21 & 106 \\
Middle phalanx & NA & 23 & 24 & 24 & 12 & 83 \\
Distal phalanx & 7 & 17 & 17 & 14 & 11 & 66 \\
\hline
\end{tabular}

${ }^{\text {a }} \mathrm{NA}=$ not applicable because structure is not present in this digit. catches, and $39 \%$ of wolves with no history of capture exhibited some foot injury (Fisher's exact $P=0.031$ ). There were highly significant differences in postmortem injury scores among capture types (Kruskal-Wallis $\left.\chi_{(2)}^{2}=11.2, P=0.004\right)$. Among wolves with foot injuries, all but one (95\%) of the wolves incidentally caught in coyote sets experienced injuries scoring moderate to severe, compared with $70 \%$ of the wolves trapped for research and $59 \%$ of wolves having no history of capture.

Postmortem evidence of previous limb injuries above the carpus/tarsus was found in 15 of 351 wolves $(4.3 \%$; $9 \%$ of the injured 166 wolves). Moderately severe or severe injuries to the feet of the same leg were found in 9 of 
those 15 wolves (60\%). Upper-limb injuries were in a forelimb in 11 of 15 (73\%) cases. All four of the upper hindlimb injuries were fractures of the tibia, fibula, and femur near the stifle joint, whereas upper forelimb injuries were more varied: scapular, three; proximal humerus, two; distal humerus, proximal radius, and proximal ulna, four; and distal radius and ulna, two. Five (45\%) of the upper forelimb injuries and one (25\%) upperhindlimb injury were associated with previous gunshot wounds, with ammunition present at the site. Only six wolves $(1.7 \%$ of the 351 wolves) with upper-limb injuries had no injuries below the carpus/tarsus; three had no previous history of capture, two were research-trapped wolves, and one was incidentally caught in a coyote set.

Where MDNR-captured wolves received foot injury scores at capture, those scores correlated poorly with their postmortem injury scores $(\rho=0.16, P=0.22)$. Restricting the comparison to scores for only the foot trapped at capture improved the correlation marginally ( $\rho=0.39, P=0.003$ ).

Among the 326 study wolves for which the remains were sufficiently well preserved for body condition to be confidently assessed at necropsy, 115 (35\%) were scored as being in very good body condition, $152(47 \%)$ good, 33 $(10 \%)$ fair, and $26(8 \%)$ poor.

Nearly $90 \%$ of the deaths among the 351 wolves in the study were attributable to five causes: killed by a vehicle (107 wolves; 30\%); shot by agency personnel while preying on livestock (96; 27\%); poached illegally (80; $23 \%)$; sarcoptic mange $(19 ; 5.4 \%)$; and killed by other wolves $(10 ; 2.8 \%)$. The remaining wolves died of a variety of other causes. Previous trap injuries were judged by the pathologist to have contributed to death in four wolves (1.1\%).

Contingency table analysis between foot injury class and cause of death stratified by body condition score found significant associations only for wolves with "very good" body condition, driven by high proportions of no or mild injuries found among wolves shot while depredating livestock (Fisher's $P=0.02$ ). No association was apparent for wolves with other causes of death. With upper-limb injuries included, results were the same (Fisher's $P=0.0005)$.

\section{Modeling}

In univariate Cox regression models, the hazard rate (essentially, the probability of dying over time) was not significantly different for

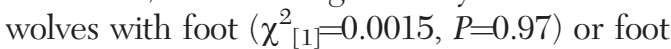
and/or upper limb $\left(\chi_{[1]}^{2}=0.0017, \quad P=0.97\right)$ injuries as compared with those without, indicating that the overall presence or absence of limb injuries had no significant effect on lifetime survival rates. Similarly, there was no difference in the survival rates after capture of either research-captured wolves or wolves caught incidentally by coyote trappers that experienced some foot $\left(\chi_{[1}^{2}=0.0016, P=0.97\right)$ or foot and/or upper limb $\left(\chi_{[1]}^{2}=0.0017\right.$, $P=0.97$ ) injury at capture vs. those that did not.

Table 4 shows results of model selection for multivariable Cox models controlling for sex, age, body condition, and capture status (research-trapped vs. incidentally trapped vs. no history of having been trapped). In the model best supported by the data, wolves with moresevere foot injuries (as indicated by higher postmortem trauma scores) had significantly higher probability of dying over time $\left(\chi^{2}=19.3\right.$, $P<0.0001)$. The magnitude of increased hazard was modest: $0.3 \%$ per 1 unit increase in trauma score; hazard ratio $(\mathrm{HR})=1.003$; $95 \%$ confidence interval (CI), 1.002-1.005, holding the other predictors constant. There was no significant difference in hazard rate by sex. However, as the age of wolves increased, their relative hazard decreased significantly $\left(\chi^{2}=186\right.$, $P<0.0001 ; \mathrm{HR}=0.014 ;$ 95\% CI, 0.007-0.026). Body condition had a significant effect on survival only for wolves in the highest category. Those in "very good" condition had about a $40 \%$ decreased risk of dying, holding other predictors constant $\left(\chi^{2}=8.8, \quad P<0.003\right.$; $\mathrm{HR}=0.40$; 95\% CI, 0.22-0.73). For competing models with substantial support that included capture status as a predictor, a wolf that was either research-caught or trapped incidentally by coyote trappers had no significant effect on survival. Best-supported models (Table 4) and 
TABLE 4. Model fit (Akaike information criterion [AIC]), difference from the best-supported model $\left(\Delta_{i}\right)^{\mathrm{a}}$ and model weights $\left(w_{i}\right)$ for Cox proportional-hazards regression models of predictors of survival time among 351 Michigan, USA, gray wolves (Canis lupus) scored ${ }^{\mathrm{b}}$ for foot injuries only and for foot and upper-limb injuries examined postmortem 2001-15.

\begin{tabular}{|c|c|c|c|c|c|c|}
\hline \multirow[b]{2}{*}{ Predictors } & \multicolumn{3}{|c|}{ Feet only } & \multicolumn{3}{|c|}{ Feet and upper limb } \\
\hline & AIC & $\Delta_{i}$ & $w_{i}$ & AIC & $\Delta_{i}$ & $w_{i}$ \\
\hline Sex, age, body condition, trauma score & 844.64 & 0 & 0.44 & 878.6 & 0 & 0.53 \\
\hline Age, body condition, trauma score, capture type & 846.06 & 1.42 & 0.21 & 880.45 & 1.85 & 0.21 \\
\hline Sex, age, body condition, trauma score, capture type & 846.12 & 1.48 & 0.21 & 880.68 & 2.08 & 0.19 \\
\hline Age, trauma score, capture type & 848.09 & 3.45 & 0.08 & 883.77 & 5.17 & 0.04 \\
\hline Sex, age, trauma score, capture type & 848.88 & 4.24 & 0.05 & 884.58 & 5.98 & 0.03 \\
\hline Age, trauma score & 853.2 & 8.56 & 0.01 & 887.99 & 9.39 & 0.01 \\
\hline Sex, age, trauma score & 853.35 & 8.71 & 0.01 & 888.26 & 9.66 & 0.00 \\
\hline
\end{tabular}

${ }^{\text {a }}$ For models with some support $\left(\Delta_{i}<10\right)$ per criteria of Burnham and Anderson (2010, p. 70).

${ }^{\mathrm{b}}$ Via International Organization for Standardization 10990-5.

the magnitude and significance of their predictors of survival were essentially identical when taking upper-limb injuries into account.

Results of model selection for multivariable, ordinal logistic-regression models of predictors of injury severity are shown in Table 5.

TABLE 5. Model fit (Akaike information criterion [AIC]), difference from the best-supported model $\left(\Delta_{i}\right)^{\mathrm{a}}$ and model weights $\left(w_{i}\right)$ for ordinal logistic regression models of foot-trauma severity class ${ }^{b}$ among 166 Michigan, USA, gray wolves (Canis lupus) with foot injuries (top) and 171 with foot and upperlimb injuries from a population of 351 wolves examined postmortem 2001-15.

\begin{tabular}{|c|c|c|c|}
\hline Predictors & AIC & $\Delta_{i}$ & $w_{i}$ \\
\hline \multicolumn{4}{|l|}{ Foot injuries only } \\
\hline $\begin{array}{l}\text { Sex+age + body condition } \\
\quad+\text { cause of death }\end{array}$ & 825.06 & 0 & 0.39 \\
\hline Age + cause of death & 825.61 & 0.55 & 0.30 \\
\hline Sex+age+cause of death & 826.16 & 1.1 & 0.23 \\
\hline Age+body condition & 829.59 & 4.53 & 0.04 \\
\hline Sex+age+body condition & 829.99 & 4.93 & 0.03 \\
\hline \multicolumn{4}{|l|}{ Foot and upper limb injuries } \\
\hline $\begin{array}{l}\text { Sex+age+body condition } \\
\text { + cause of death }\end{array}$ & 822.03 & 0 & 0.77 \\
\hline Age+body condition & 826.02 & 3.99 & 0.11 \\
\hline Sex+age+body condition & 827.02 & 4.99 & 0.06 \\
\hline Age + cause of death & 828.08 & 6.05 & 0.04 \\
\hline Sex+age + cause of death & 829.12 & 7.09 & 0.02 \\
\hline
\end{tabular}

Considering foot injuries only, the closeness of the rankings of the top-three models suggests the most parsimonious, with only age and cause of death as predictors, is likely the best-supported model per Arnold (2010). In that model, for each year of increasing age, the odds of having a severe foot injury compared with a less-severe foot injury increased by $20 \%$ (odds ratio $[\mathrm{OR}]=1.20$; 95\% CI, 1.1-1.3). Wolves killed during depredation of livestock were about half as likely to have had a severe foot injury $(\mathrm{OR}=0.45 ; 95 \% \mathrm{CI}, 0.21-0.97)$ as wolves dying of other causes. There were no other significant associations between causes of death and foot injury severity. With upperlimb injuries included in the analysis, the full model with age, sex, body condition, and cause of death as predictors was clearly best supported (Table 5). There, the effect of age was similar to the foot-injury-only model $(\mathrm{OR}=1.26 ; 95 \% \mathrm{CI}, 1.1-1.4)$, and being in any body condition other than poor was associated with significantly decreased odds of having a severe injury ("fair" vs. "poor": $\mathrm{OR}=0.32 ; 95 \%$ CI, 0.11-0.93; "good" vs. "poor": $\mathrm{OR}=0.17 ; 95 \% \mathrm{CI}, 0.06-0.47$; "very good" vs. "poor": $\mathrm{OR}=0.21 ; 95 \%$ CI, $0.07-$ 0.59). There was no significant association between sex or cause of death and the severity of limb injury. 


\section{DISCUSSION}

A variety of studies describing foot injuries in both wildlife (Englund 1982; Warburton 1992; Logan et al. 1999; Powell 2005; Munoz-Igualada et al. 2008; Elbroch et al. 2013), particularly coyotes (Olsen et al. 1986; Onderka et al. 1990; Phillips et al. 1996; Shivik et al. 2000, 2005; Darrow et al. 2009), and domestic dogs (e.g., Basher 1994; Libardoni et al. 2016; Isaksen et al. 2020) exist. Relatively few studies have described injuries in wolves, and these have compared injuries incurred using different types of traps in known-trapped animals, rather than epidemiologically surveying a broader population (Van Ballenberghe 1984; Kuehn et al. 1986; Sahr and Knowlton 2000; Frame and Meier 2007).

Age might be expected to affect rates and severity of foot injuries, and age was the most consistent and important predictor of both survival and injury severity in this study. In studies of wolves in which the effect of age was examined, pups generally had fewer injuries (Kuehn et al. 1986) and fewer severe injuries (Van Ballenberghe 1984; Kuehn et al. 1986). There was no significant difference between the proportion of pups (younger than $1 \mathrm{yr}$ ) with injuries $(14 / 40,35 \%)$ and that of adults (159/311, $51 \%$; Fisher's exact $P=0.29)$ in our study. In multivariable models with other potential explanatory factors controlled, increasing age was associated with more-severe injury, and severity with decreased survival, although the increased risk in dying was modest $(0.3 \%$ per unit increase in postmortem trauma score). Overall, having a foot injury or not had no epidemiologically detectable effect on survival, suggesting that, in Michigan, foot injuries are not generally an important factor in wolf mortality.

Risks of dying over time (hazard rates) in our study were inversely related to age and agree with a large concurrent survival study of another subpopulation (telemetered wolves) from the same population studied here. That study found reduced survival up to about 5 yr of age (O'Neil et al. 2017; Fig. 2a). They attributed the increased mortality risk to lack of experience dealing with human encounters, noting that anthropogenic mortality outnumbered other causes more than two to one. In this study of the broader wolf population, three anthropogenic causes accounted for more than $80 \%$ of deaths. Controlling for other factors, body condition was an inconsistent predictor of both survival and injury severity, associated primarily with wolves in the best condition preying on livestock, and with decreased risk of severe upper-limb injuries, which were rare. In general, assessing the frequency and severity of upper-limb injuries added little explanatory information, suggesting that scoring foot injuries alone quite adequately summarized the importance of trap injuries to wolf survival in the Michigan population.

Our data suggested relatively low agreement between foot injury scores assessed at the time of trapping and those assessed postmortem. Typically, injury scores at capture underestimated postmortem scores. Trappers can assess only the injuries they see, yet wolves may be caught more than once in their lifetimes. About $13 \%$ (10/75) of wolves captured by MDNR research trappers were caught more than once. Wolves may be caught and escape unseen. Those injuries go unrecorded. Veterinarians or others experienced in assessing injuries may not be present at trapping, and consequently, injuries may be misjudged. Although partially rectifiable with training (which all MDNR trappers had undergone), some injuries (Fig. 1) may appear externally only as soft tissue swelling at the time of trapping, and trappers do not have radiography. Our results suggest that assessments at capture do not necessarily predict the ultimate extent of an animal's impairment (or lack thereof).

The limitations of our study should be borne in mind. Our sample was systematic and of long duration, but not random, and we could not recover for examination every wolf that died in Michigan. Thus, it is possible our results are not representative of the broader population, although confounding factors that would have affected both foot injuries and recovery of carcasses are not obvious. Radio- 


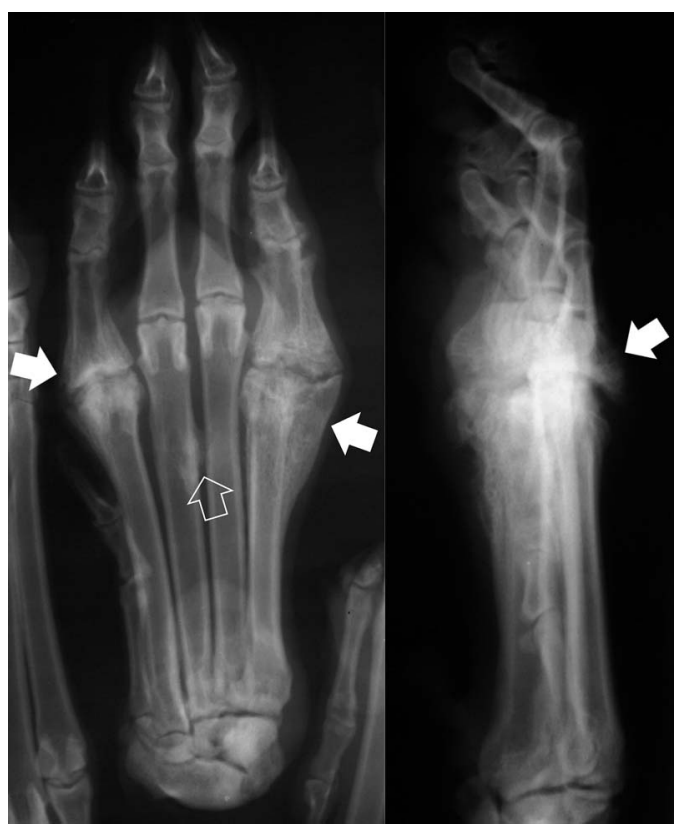

Figure 1. Dorsopalmar (left) and lateral radiographic views of the right front foot of a male gray wolf (Canis lupus) that had been trapped in July 2004 and was collected dead in January 2006 in Schoolcraft County, Michigan, USA. The animal was estimated to be about $7 \mathrm{yr}$ old at the time of death. He was scored at capture as having only minor edematous soft tissue swelling. On postmortem examination, however, bony callus surrounded the metacarpal phalangeal joints of digits II and V (solid arrows) and periosteal proliferation partially bridged the midshafts of metacarpals III and IV (open arrow). The metacarpal phalangeal joint of $\mathrm{V}$ was fused.

graphic signs of extremely subtle injuries could conceivably have been overlooked because a board-certified radiologist was not involved. However, radiographs were all read by a clinically experienced veterinarian with standard radiologic training. Any lesion sufficiently subtle to be missed seems unlikely to have materially changed these results.

\section{ACKNOWLEDGMENTS}

We thank MDNR Upper Peninsula field staff for help collecting wolf carcasses, M. Tubbs for radiographic assistance, and S. Mayhew and S. Winterstein for statistical consultations. This work was supported by the Federal Aid in Wildlife Restoration Act under Michigan Pittman-Robertson Project W-147-R.

\section{LITERATURE CITED}

Arnold TW. 2010. Uninformative parameters and model selection using Akaike's information criterion. J Wildl Manage 74:1175-1178.

Baker RH. 1983. Gray wolf Canis lupus (Linnaeus). In: Michigan mammals, Baker $\mathrm{RH}$, editor. Michigan State University Press, East Lansing, Michigan, pp. 401-412.

Basher A. 1994. Foot injuries in dogs and cats. Compend Contin Educ Pract Vet 16:1159-1176.

Beyer DE, Peterson RO, Vucetich JA, Hammill JH. 2009. Wolf population changes in Michigan. In: Recovery of gray wolves in the Great Lakes region of the United States, Wydeven AP, Van Deelen TR, Heske EJ, editors. Springer, New York, New York, pp. 65-85.

Burnham KP, Anderson DR. 2010. Model selection and multimodel inference: A practical information-theoretic approach. 2nd Ed. Springer-Verlag, New York, New York, 489 pp.

Darrow PA, Skirpstunas RT, Carlson SW, Shivik JA. 2009. Comparison of injuries to coyote from 3 types of cable foot-restraints. J Wildl Manage 73:1441-1444.

Elbroch LM, Jansen BD, Grigione MM, Sarno RJ, Wittmer HU. 2013. Trailing hounds vs foot snares: comparing injuries to pumas Puma concolor captured in Chilean Patagonia. Wildl Biol 19:210-216.

Englund J. 1982. A comparison of injuries to leg-hold trapped and foot-snared red foxes. J Wildl Manage 46:1113-1117.

Frame PF, Meier TJ. 2007. Field-assessed injury to wolves captured in rubber-padded traps. J Wildl Manage 71:2074-2076.

Gese EM, Terletzky PA, Erb JD, Fuller KC, Grabarbkewitz JP, Hart JP, Humpal C, Sampson BA, Young JK. 2019. Injury scores and spatial response of wolves following capture: Cable restraints versus foothold traps. Wildl Soc Bull 43:42-52.

Isaksen KE, Linney L, Williamson H, Cave NJ, Norman EJ, Cogger N. 2020. TeamMate: A longitudinal study of New Zealand working farm dogs. II. Occurrence of musculoskeletal abnormalities. Front Vet Sci 7:624.

ISO (International Organization for Standardization). 1999. ISO 10990-5:1999 Animal (mammal) trapsPart 5: Methods for testing restraining traps. International Organization for Standardization, Geneva, Switzerland, 20 pp. https:/www.iso.org/ standard/26569.html. Accessed October 2021.

Kreeger TJ, Arnemo JM. 2018. Handbook of wildlife chemical immobilization. 5th Ed. International Wildlife Veterinary Services, Inc, Laramie, Wyoming, 472 pp.

Kuehn DW, Fuller TK, Mech LD, Paul WJ, Fritts SH, Berg WE. 1986. Trap-related injuries to gray wolves in Minnesota. J Wildl Manage 50:90-91.

Libardoni RN, Serafini GMC, de Oliveira C, Schimites PI, Chaves RO, Feranti JPS, Costa CAS, do Amaral AS, Raiser AG, Soares AV. 2016. Appendicular fractures of traumatic etiology in dogs: 955 cases (2004-2013). Cienc Rural 46:542-546. 
Logan KA, Sweanor LL, Smith JF, Hornocker MG. 1999. Capturing pumas with foot-hold snares. Wildl Soc Bull 27:201-208.

Matson GM. 1981. Workbook for cementum analysis. Matson's Laboratory, Milltown, Montana, $30 \mathrm{pp}$.

MDNR (Michigan Department of Natural Resources). 2008. Michigan wolf management plan. Wildlife Division Report No. 3484. Michigan Department of Natural Resources, Lansing, Michigan, 18 pp. https:// www.michigan.gov/documents/dnr/Michigan_Wolf_ Management_Plan_474433_7.pdf. Accessed October 2020.

MDNR. 2015. Michigan 2008 wolf management plan: Summary of management accomplishments. Michigan Department of Natural Resources, Wildlife Division, Lansing, Michigan, $11 \mathrm{pp}+6$. https:// www.michigan.gov/documents/dnr/wolf_plan_ accomplishments_482754_7.pdf. Accessed October 2020.

Mech, LD. 1974. Current techniques in the study of elusive wilderness carnivores. In: Proceedings of the 11th congress of the International Union of Game Biologists, Kjerner I, Bjurholm P, editors. International Union of Game Biologists, Stockholm, Sweden, pp. 315-322.

Muñoz-Igualada J, Shivik JA, Dominguez FG, Lara J, Gonzalez LM. 2008. Evaluation of cage-traps and cable restraint devices to capture red foxes in Spain. J Wildl Manage 72:830-836.

Olsen GH, Linhart SB, Holmes RA, Dasch GJ, Male CB. 1986. Injuries to coyotes caught in padded and unpadded steel foothold traps. Wildl Soc Bull 14: 219-223.

Onderka DK, Skinner DL, Todd AW. 1990. Injuries to coyotes and other species caused by four models of footholding devices. Wildl Soc Bull 18:175-182.

O’Neil ST, Bump JK, Beyer DE Jr. 2017. Spatially varying density dependence drives a shifting mosaic of survival in a recovering apex predator (Canis lupus). Ecol Evol 7:9518-9530.

Phillips RL, Gruver KS, Williams ES. 1996. Leg injuries to coyotes captured in three types of foothold traps. Wildl Soc Bull 24:260-263.

Potvin MJ, Drummer TD, Vucetich JA, Beyer DE, Peterson RO, Hammill JH. 2005. Monitoring and habitat analysis for wolves in Upper Michigan. J Wildl Manage 69:1160-1169.
Powell RA. 2005. Evaluating welfare of American black bears (Ursus americanus) captured in foot snares and in winter dens. J Mammal 86:1171-1177.

R Core Team. 2018. R: A language and environment for statistical computing. R Foundation for Statistical Computing, Vienna, Austria.

Sahr DP, Knowlton FF. 2000. Evaluation of tranquilizer trap devices (TTDs) for foothold traps used to capture gray wolves. Wildl Soc Bull 28:597-605.

Shivik JA, Gruver KS, DeLiberto TJ. 2000. Preliminary evaluation of new cable restraints to capture coyotes. Wildl Soc Bull 28:606-613.

Shivik JA, Martin DJ, Pipas MJ, Turnan JT, DiLiberto TJ. 2005. Initial comparison: Jaws, cables, and cage-traps to capture coyotes. Wildl Soc Bull 33:1375-1383.

Sisson S. 1975. Chapter 48: Carnivore osteology. In: Sisson and Grossman's: The anatomy of the domestic animals, 5th Ed., Getty R, editor. W. B. Saunders Company, Philadelphia, Pennsylvania, pp. 14271503.

Stokes ME, Davis CS, Koch GG. 1995. 9.2. Ordinal response: Proportional odds model. In: Categorical data analysis using the SAS System. SAS Institute Inc., Cary, North Carolina, pp. 217-233.

USFWS (US Fish and Wildlife Service). 2019. Endangered and threatened wildlife and plants; Removing the gray wolf (Canis lupus) from the list of endangered and threatened wildlife (proposed rule). Federal Register 84:9648-9687.

Van Ballenberghe V. 1984. Injuries to wolves sustained during live-capture. J Wildl Manage 48:1425-1429.

Vucetich JA, Huntzinger BA, Peterson RO, Vucetich LM, Hammill JH, Beyer DE Jr. 2012. Intra-seasonal variation in wolf Canis lupus kill rates. Wildl Biol 18:235-245.

Warburton B. 1992. Victor foot-hold traps for catching Australian brushtail possums in New Zealand: capture efficiency and injuries. Wildl Soc Bull 20: 67-73.

White HB, Batcheller GR, Boggess EK, Brown CL, Butfiloski JW, Decker TA, Erb JD, Fall MW, Hamilton DA, Hiller TL, et al. 2021. Best management practices for trapping furbearers in the United States. Wildl Monogr 207:3-59.

Submitted for publication 15 February 2021. Accepted 27 August 2021. 